Biljana Koturevic, Borivoj Adnadjevic* and Jelena Jovanovic

\title{
The kinetics of the extraction of caffeine from guarana seed under the action of ultrasonic field with simultaneous cooling
}

https://doi.org/10.1515/gps-2020-0003

Received April 10, 2019; accepted September 04, 2019.

Abstract: The kinetics of isothermal extraction of caffeine from guarana seed under the action of ultrasonic field with simultaneous cooling (UESC) was investigated. The isothermal kinetics curves were measured at temperatures range $T=17-58^{\circ} \mathrm{C}$. Using the model-fitting method it was determined that the kinetics of caffeine extraction can be described by a theoretical Jander threedimensional diffusional model. The values of the rate constant were calculated for different temperatures, as well as the kinetic parameters (activation energy $\left(E_{2}\right)$ and preexponential factor $(\ln A)$ ). Based on the results obtained, it is concluded that the rate constants of caffeine extraction under UESC are about 2 times higher in comparison to the values obtained for the extraction in the conditions of conventional heating $(\mathrm{CH})$. The activation energy of the caffeine extraction under the UESC $\left(E_{\mathrm{a}}^{\text {UESC }}=19.4 \mathrm{~kJ} \cdot \mathrm{mol}^{-1}\right)$ is lower than the values are for $\mathrm{CH}\left(E_{\mathrm{a}}^{\mathrm{CH}}=21.8 \mathrm{~kJ} \cdot \mathrm{mol}^{-1}\right)$. Energy consumption for UESC is four times lower than for $\mathrm{CH}$ conditions. It is shown that there is a linear correlation relationship between kinetic parameters obtained for UESC and $\mathrm{CH}$ conditions. The changes in the values of kinetic parameters are explained by the model of selective transfer of energy from the reaction system to the reactant molecules.

Keywords: caffeine; extraction; kinetics; simultaneous cooling; ultrasonic field

\footnotetext{
* Corresponding author: Borivoj Adnadjevic, Faculty of Physical Chemistry, University of Belgrade, Studentski trg 12-16, Belgrade 11001, Serbia, e-mail: bora@ffh.bg.ac.rs, Tel. +381638188382 Biljana Koturevic, University of Criminal investigation and Police Studies, Cara Dusana 196, 11080 Belgrade, Zemun, Serbia Jelena Jovanovic, Faculty of Physical Chemistry, University of Belgrade, Studentski trg 12-16, Belgrade 11001, Serbia
}

\section{Introduction}

Guarana (Paullinia cupana, Sapindaceae) is Amazon forests plant recognized by characteristic red capsulated fruit which contains few dark brown seeds. Although initially guarana was consumed internally by the Amazon population, later it became accepted worldwide as a medicinal plant with a lot of pharmacological effects [1]. These pharmacological effects of guarana can beattributed to the numerous active substances which are present mainly in guarana seed, and those are methylxanthine (caffeine, theophylline and theobromine), polyphenols, tannins, catechins, saponins, polysaccharides, and so forth [2]. Considering the high content of caffeine (from $3-7 \%$ ) [3], guarana is one of the most crucial caffeine source, a substance with many applications in the food and pharmaceutical industry where it is used due to the stimulatory effects on the metabolism, central nervous system, and gastrointestinal and respiratory systems. Caffeine also acts as a vasodilator and diuretic, increases energy, cognitive performance and neuromuscular coordination $[4,5]$.

A lot of different techniques for caffeine extraction were described in the literature. Although conventional extractions (CE) of caffeine have been used for decades, due to numerous drawbacks, various novel extraction techniques have been employed for the improvement of solvent extraction. Among them, the ultrasound-assisted (UAE) and microwave-assisted extraction (MAE) are techniques whose usage is increasing owing to the fact that these techniques can lead to the intensification of processes. That is mainly attributed to the physical and chemical effects of ultrasound and microwave fields on the kinetics of chemical reactions and physicochemical processes.

The articles about the application of MAE for caffeine extraction are extensively searched and mentioned in our previous work [6]. Also, the isothermal MAE of caffeine from guarana seed was accomplished and presented in our previous work [7].

The ultrasound-assisted extraction (UAE) is described in the literature as a technique that offers advantages in 
extraction, such as reduction of extraction time, improved quality of extract and energy efficient [8]. The action of ultrasonic field is related to the chemical effects (forming different kinds of reactive radicals $\left.\mathrm{H}^{\circ},{ }^{\circ} \mathrm{OH},{ }^{\circ} \mathrm{OOH}\right)$ and physical effects (microstreaming, microturbulence, liquid microjets) of this field in solid-liquid systems which are caused by cavitation phenomenon [9].

The knowledge of the kinetics of extraction (kinetics model, kinetic parameters, kinetics complexity) is essential since it represents the basis for the simulation, control, development and advancement of the extraction technologies. To describe the kinetics of solid-liquid extraction of various bioactive compounds from plant material, empirical models such as Peleg equation [10], Ponomaryov equation [11], So and Mcdonald model [12], and Patricelli model [13] is proposed. Theoretical models which are applied for describing the solvent extractions include different order-based models [14-16], and the analytical solution of Fick's second law of diffusion $[17,18]$. Furthermore, for modelling the solid-liquid extractions two-parametric theoretical models which are derived from Fick's law such as film theory and unsteady state diffusion [11,19] are also used. However, no relevant kinetic model of caffeine extraction under the UESC has been reported.

Knowing that there are no available literature data about the extraction under the action of ultrasonic field with simultaneous cooling (UESC), which is necessary for objective determination of the effects of an ultrasonic field, in this work the kinetics of caffeine extraction from guarana seed (i.e. kinetics model, kinetic parameters, kinetics complexity) under the UESC was investigated.

\section{Materials and methods}

\subsection{Plant material and chemical reagents}

Powdered guarana seeds were purchased from the local market in Brazil. The total content of caffeine in guarana seed $(4.78 \% \mathrm{w} / \mathrm{w})$, the moisture content $(7.8 \%)$ and particle size $(\mathrm{dp} \leq 250 \mu \mathrm{m})$ were determined and provided in our previous work [7].

Hydrochloric acid (36\%) and sulphuric acid (98\%) both p.a grade were purchased from Zorka Pharma (Šabac, Serbia). Lead acetate anhydrous ( $\geq 33 \%$ basic $\mathrm{Pb}$ as $\mathrm{PbO}$ ) (p.a.) was supplied from Carlo Erba (Milano, Italy). Caffeine, laboratory grade, was procured from Fisher Scientific UK, Bishop Meadow Road, Leics, LE11 5RG, UK.

\subsection{Extraction of caffeine from guarana seed under the action of ultrasonic field with simultaneous cooling}

Extraction of caffeine from guarana seed under the action of ultrasonic field with simultaneous cooling (UESC) was carried out in various temperature within the range of $17-58^{\circ} \mathrm{C}\left( \pm 1.0^{\circ} \mathrm{C}\right)$ using a thermostatically controlled ultrasonic reactor (Model VC 750 made by Sonics and Materials Inc. USA; with $20 \mathrm{kHz}$ working frequency and $750 \mathrm{~W}$ - amplitude setting displayed in \% on the scale of 10-100). The ultrasonic reactor consists of a titanium alloy ultrasonic probe with a $13 \mathrm{~mm}$ diameter tip. The schematic representation of ultrasonic reactor with simultaneous cooling system is presented on Figure 1.

The guarana seed powder $(1.0 \mathrm{~g})$ was added to distilled water $(80 \mathrm{~mL})$ at a predetermined temperature. An ultrasonic probe was submerged in the extraction suspension at about $5 \mathrm{~cm}$ depth. The temperature was controlled using a thermometer which was placed within the extraction suspension at the same depth as the ultrasonic probe. The described ultrasonic reactor is modified in order to provide isothermal conditions, so the extraction suspension is simultaneously cooled by using a double-walled reaction vessel. In predominated time intervals, aliquots were collected from the extraction mixture and filtered using the Munktell No. 8 filter paper, (Munktell, Grycksbo, Sweden). All the aliquots were collected from the same area of extraction mixture all the time. All the extractions were performed in triplicate and average value has been reported in the figures.

\subsection{Determination of caffeine concentration in the extract}

Since guarana contains tannins which could interfere with the determination of caffeine, the removal of tannins from extract was achieved by using a method with a leadacetate solution for precipitation of tannins which is proposed and developed by Yao et al. [20].

The absorbance of the caffeine solution was measured at a wavelength of $274 \mathrm{~nm}$ using a UV-Vis spectrophotometer, Agilent Technologies, US. The caffeine concentration $\left(C\right.$, $\left.\left(\mathrm{mg} \cdot \mathrm{L}^{-1}\right)\right)$ was determined using a standard curve of caffeine $\left(0-1000 \mathrm{mg} \cdot \mathrm{L}^{-1}\right)$ as described in our previous work [7].

\subsection{Determination of extraction degree}

The degree of extraction $(\alpha)$ was determined by the expression: 


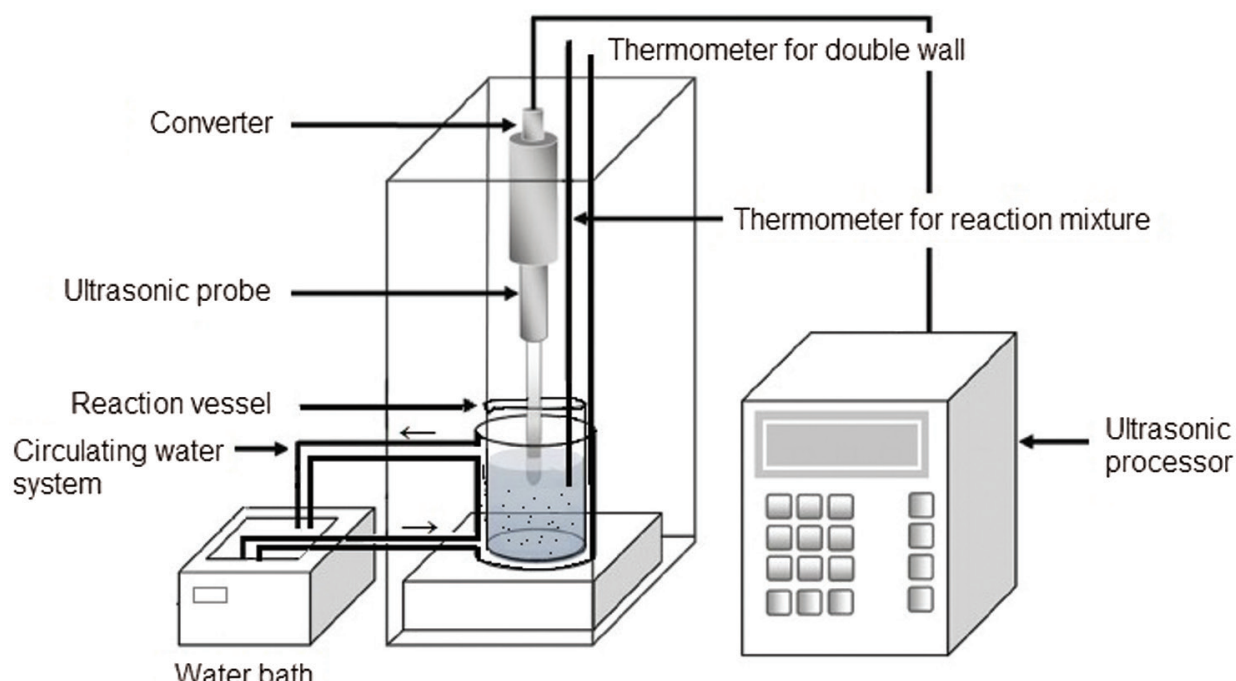

Figure 1: The scheme of ultrasonic reactor with simultaneous cooling system.

$$
\alpha=C / C_{\max }
$$

where $C\left(\mathrm{mg} \cdot \mathrm{L}^{-1}\right)$ is the concentration of caffeine in water extract in the time interval $t$, and $C_{\max }$ is the maximal concentration of caffeine in water extract which is calculated concerning the total content of caffeine in guarana seed $(4.78 \% \mathrm{w} / \mathrm{w})$. The total content of caffeine in guarana seed was established by applying the method for determining the total concentration of caffeine in tea and coffee proposed by Wanyika et al. [21].

\subsection{Energy consummation}

Energy consummation is defined to quantify the required energy to obtain $1 \mathrm{~g}$ of product (caffeine) in terms of efficiency. Energy efficiency $\left(E_{\text {eff }}\right)$ is calculated using equation:

$$
E_{\text {eff }}=\frac{\text { weight of caffeine }(g)}{\text { Energy })}
$$

\subsection{Methods for kinetic analysis}

\subsubsection{The single-step approximation}

The kinetics of the processes with the participation of the solid phase is usually unknown, complex and they tend to occur in multiple steps. For the mathematically describing such types of the processes, the knowledge about the mechanism of that process is required, which means knowing the order of the occurring the elementary stages of the progress of the complex reaction. When the mechanism of the complex reaction is known, their kinetics may be described with a set of differential kinetics equations of each particular elementary stage of the overall reaction.

On the contrary to this, the single-step approximation (SSA) [22], starts from the assumption that: a) the rate of kinetically complex reaction $(\mathrm{d} \alpha / \mathrm{dt})$ depends only on the temperature (T) and the degree of conversion/extraction $(\alpha)$ and, b) the rate of a reaction or process can be presented as a product of two independent functions $k(\mathrm{~T})$ and $f(\alpha)$.

In that case, the rate of the multi-stage reaction can be described with the following expression:

$$
d \alpha / d t=k(T) \cdot f(\alpha)
$$

where $k(\mathrm{~T})$ is a rate constant which depends solely on temperature and usually is expressed by the Arrhenius equation and $f(\alpha)$ which is an analytical expression describing the kinetic model of the deliberate process. In that way, the SSA enables to describe the kinetics of complex reaction with only one general equation for the rate of the process, instead of using a set of differential equations.

\subsubsection{Friedman differential isoconversional method}

The dependences of the activation energy $\left(E_{\mathrm{a}}\right)$ on the extraction degree $(\alpha)$ for the investigated process of caffeine extraction under UESC were established by the Friedman differential isoconversional method [23]. This method is based on single-step approximation and 
isoconversional principle, according to which the reaction rate at a constant extraction rate $(\alpha)$ is only a function of temperature. According to this method, the logarithm form of rate equation can be expressed as:

$$
\ln \left(\frac{d \alpha}{d t}\right)_{\alpha}=\ln \left[A_{\alpha} \cdot f(\alpha)\right]-\left(\frac{E_{\mathrm{a}, \alpha}}{R T_{\alpha}}\right)
$$

where $(\mathrm{d} \alpha / \mathrm{dt}) \alpha$ is the reaction/process rate, which is specifically here the rate of extraction at given extraction degree $(\alpha), \mathrm{T}_{\alpha}$ is the temperature when extraction degree on certain temperature regime is achieved, $A_{\alpha}$ is the preexponential factor on given extraction degree, $E_{\mathrm{a}, \mathrm{\alpha}}$ is the activation energy on given extraction degree, and $R$ is the gas constant. By plotting the dependence of $\ln (d \alpha / d T)_{\alpha}$ versus $T^{-1}$ (Eq. 4), the values of activation energies of extraction of caffeine under the UESC at different values of $\alpha$ can be provided. Besides, the dependence of $E_{\mathrm{a}}$ vs $\alpha$ helps to disclose the complexity of the investigated process.

\subsubsection{Model-fitting method}

The model-fitting method is used to establish the kinetic model ofinvestigated extraction process [24]. In accordance with this method, the experimentally obtained conversion curve (the dependence of the degree of extraction on time $(\alpha=f(t))$ is transformed into experimental normalized conversion curve $\left(\alpha=f\left(t_{\mathrm{n}}\right)\right)$, where $t_{\mathrm{n}}$ is the normalized time defined as: $t_{\mathrm{n}}=\mathrm{t} / \mathrm{t}_{0.9}$, and $t_{0.9}$ is the time when the degree of extraction of 0.9 is reached.

By using the model-fitting method, kinetic model of investigated reaction/process is determined by comparing normalized experimentally conversion curve of reaction/ process $\left(\alpha=f\left(t_{\mathrm{n}}\right)\right)$ with the normalized conversion curves of chosen theoretical and empirical models $\left(\alpha_{\mathrm{iM}}=f\left(t_{\mathrm{n}}\right)\right)$. For the defined set of $t_{\mathrm{n}}$ values in the range from 0-1, with 0.05 step, the sum of the squares of the deviation of each of the selected models from the experimental normalized conversion curve is calculated. The theoretical or empirical kinetic model whose sum of squares of deviation from the normalized experimentally conversion curve gives minimal values is accepted for the kinetic model of the investigated reaction/process.

\subsubsection{Kinetic models of solid-liquid extraction}

Based on the available literature data, the commonly employed kinetic models for modelling the kinetics of the solid-liquid extraction process under the conditions of conventional heating and ultrasonic field are: a) the Spiro reaction model [15]; b) Fick's second law of diffusion [17,18]; and c) unsteady state diffusion through plant material [19].

Spiro et al. [15] used the theoretical model which is based on the assumption that extraction kinetics can be described by a first-order chemical reaction, to describe the kinetics of conventional solid-liquid extraction of caffeine from tea leaves.

The linear form of a kinetic model proposed by Spiro is given by expression [15]:

$$
\ln \left(C_{\infty} /\left(C_{\infty}-C\right)\right)=k_{s} \cdot t+\alpha
$$

where the $C_{\infty}$ is an equilibrium concentration of caffeine $(\mathrm{g} / \mathrm{L})$ at the highest temperature, and the $C$ is the concentration of caffeine at time $t(\mathrm{~min}), k_{\mathrm{s}}$ is firstorder rate constant $\left(\mathrm{min}^{-1}\right)$, and $\alpha$ is an integration constant.

Tao et al. [18] described the kinetics of ultrasoundassisted solid-liquid extraction of phenolic compounds from grape marc using theoretical model based on Fick's second law of diffusion.

The linear form of a diffusion model derived from the Fick's second law is expressed as follows [18]:

$$
\ln \frac{M_{\infty}}{M_{\infty}-M_{t}}=\ln \frac{\pi^{2}}{6}+\frac{D_{e} \pi^{2} t}{R^{2}}
$$

where the $M_{\infty}$ is the maximum amount of solute $(\mathrm{mg} / \mathrm{g})$ extracted after the infinite time; the $M_{t}$ is the amount of solute $(\mathrm{mg} / \mathrm{g})$ extracted from raw materials at time $t$; the $D_{e}$ is the solute effective diffusion coefficient $\left(\mathrm{m}^{2} / \mathrm{s}\right) ; t$ is time (s); and the $R$ is the radius of particles (m).

Veličković et al. [11] and Stanisavljević et al. [19] used the two-parameter theoretical kinetic model, the unsteady state diffusion through plant material, to model the kinetics of ultrasound-assisted solid-liquid extraction of various substances from garden and glutinous sage, and oil from tobacco seeds, respectively.

The linear form of unsteady state diffusion model can be expressed as [19]:

$$
\ln \frac{q}{q_{0}}=\ln \left(1-b^{\prime}\right)-k^{\prime} \cdot t
$$

where the $q$ is the content of the caffeine in the guarana seeds during the extraction $(\mathrm{g} / 100 \mathrm{~g})$; the $q_{0}$ is the content of caffeine initially present in the guarana seeds $(\mathrm{g} / 100 \mathrm{~g})$; the $b^{\prime}$ is the washing coefficient, the $k^{\prime}$ is the slow extraction coefficient, $\left(\mathrm{min}^{-1}\right)$; and $t$ is the time (min). 


\section{Results and discussion}

Figure 2 shows the kinetic curves of extraction of caffeine under the UESC (dependence of $C$ vs time), at different temperatures.

The kinetic curves of caffeine extraction under the UESC at all the examined temperatures have the same complex shape. It can be noticed that with raising the temperature of extraction, the concentration of caffeine is increasing (from $0.448 \mathrm{~g} \cdot \mathrm{L}^{-1}$ at $17^{\circ} \mathrm{C}$ to $0.534 \mathrm{~g} \cdot \mathrm{L}^{-1}$ at $58^{\circ} \mathrm{C}$ ), and the duration of linear changes and time required to achieve the plateau are reducing.

Since the kinetics of extraction is commonly modelled with kinetic models: Spiro model, Fick's second law of diffusion, and model of unsteady state diffusion through plant material, the possibility of modelling the kinetics of extraction of caffeine under the UESC by using these models were investigated. The linearized forms of the evaluated kinetic models are shown in Figures 3a-c.

According to the results presented in Figures 3a-c, the linearized forms of all the investigated model equations didn't fit the experimental data very well during the whole process at all studied temperatures. Therefore, the kinetics of caffeine extraction under the UESC cannot be modelled by the above examined kinetic models.

In order to explore the possibility of employing the SSA on the kinetics of extraction of caffeine from guarana seed under the UESC, the shape of the dependence of $\mathrm{d} C / \mathrm{d} t$ vs degree of extraction was investigated. Figure 4 illustrates the change of $\mathrm{d} C / \mathrm{d} t$ on the degree of extraction at different temperatures.

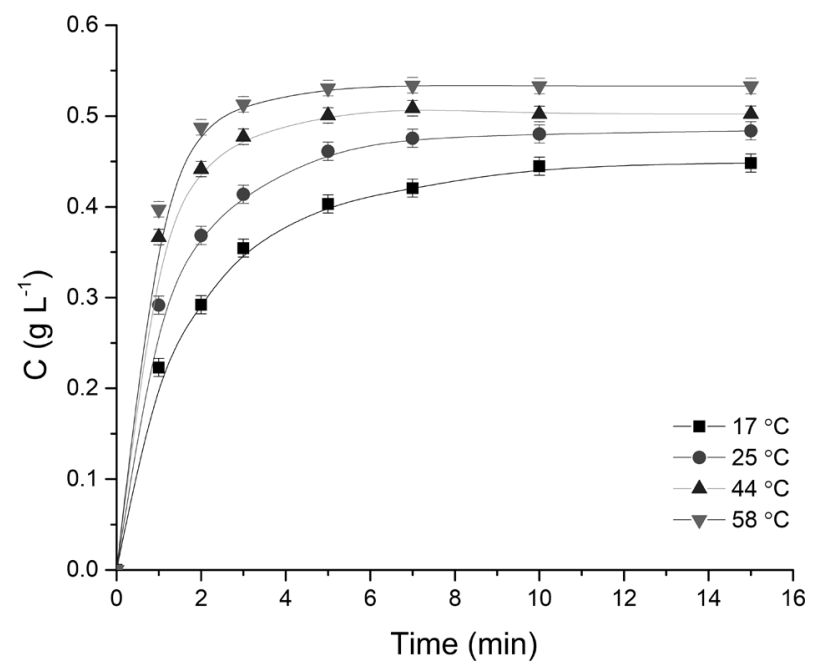

Figure 2: The kinetic curves of caffeine extraction from guarana seed under the action of UESC (Results are presented as means \pm standard deviations).
As can be noticed from Figure 4 the shape of the dependence $\mathrm{d} C / \mathrm{d} t$ on $\alpha$ does not change with the change in temperature. The temperature independence of the shape of $\mathrm{d} C / \mathrm{d} t$, and on $\alpha$ confirms that the reaction model does not change and thus indicates that it is possible to apply single-step approximation for describing the kinetics of extraction of caffeine from guarana seed under the UESC.

In accordance with Friedman isoconversional method, the dependence of $\ln (\mathrm{d} \alpha / \mathrm{d} t) \alpha$ on $1 / T\left(\mathrm{~K}^{-1}\right)$ is shown on Figure 5.

As can be seen from the results presented in Figure 5, there was a linear relationship between $\ln (d \alpha / d t) \alpha$ and $1 / T$ for all degrees of caffeine extraction. With that in mind, from the slopes and intercepts of these straight lines, the values of the kinetic parameters $\left(E_{\mathrm{a}, \alpha}\right.$ and $\left.\ln A_{\alpha}\right)$ for different degrees of caffeine extraction were calculated. The dependency of the activation energy on the degree of caffeine extraction was determined (Figure 6).

As can be observed from Figure 6, the value of activation energy determined by Friedman's differential isoconversional method is independent on the degree of caffeine extraction. This confirms that there is one ratelimiting step of the investigated extraction process with a calculated value of $E_{\mathrm{a}, \alpha}=19.00 \pm 2.7 \mathrm{~kJ} \cdot \mathrm{mol}^{-1}$.

The independence of $E_{\mathrm{a}, \alpha}$ on $\alpha$ enabled applying the model-fitting method for determining the correct kinetic model of the caffeine extraction under the action of UESC. By analyzing the sum of squares of the deviation between the experimental normalized conversional curve, and the normalized theoretical model conversional curve, it can be concluded that the investigated kinetics can be modelled by Jander three-dimensional diffusional (3D) model [25], which is given by the following equation:

$$
\left[1-(1-\alpha)^{1 / 3}\right]^{2}=k_{M} \cdot t
$$

where $k_{\mathrm{M}}$ is model rate constant. If the previous statement is correct, the dependence of $\left[1-(1-\alpha)^{1 / 3}\right]^{2}$ vs time should be linear. This dependence is shown in Figure 7.

From Figure 7 it can be seen that for all studied temperatures, the plot of $\left[1-(1-\alpha)^{1 / 3}\right]^{2}$ on the extraction time resulted in a linear function throughout the entire range of investigated extraction process. The suitability of the chosen kinetic model for fitting the experimental data of caffeine extraction under the UESC can be proved with a high value of $\mathrm{R}_{\text {adj }}{ }^{2}$ coefficient, which is between 0.994 and 0.997. Therefore, it can be concluded that the Jander 3D model is appropriate for describing the extraction of caffeine from guarana seed under the UESC.

Several possible mass transfer mechanism has been proposed in order to model the extraction of active substance from some plant material: a) entry of 

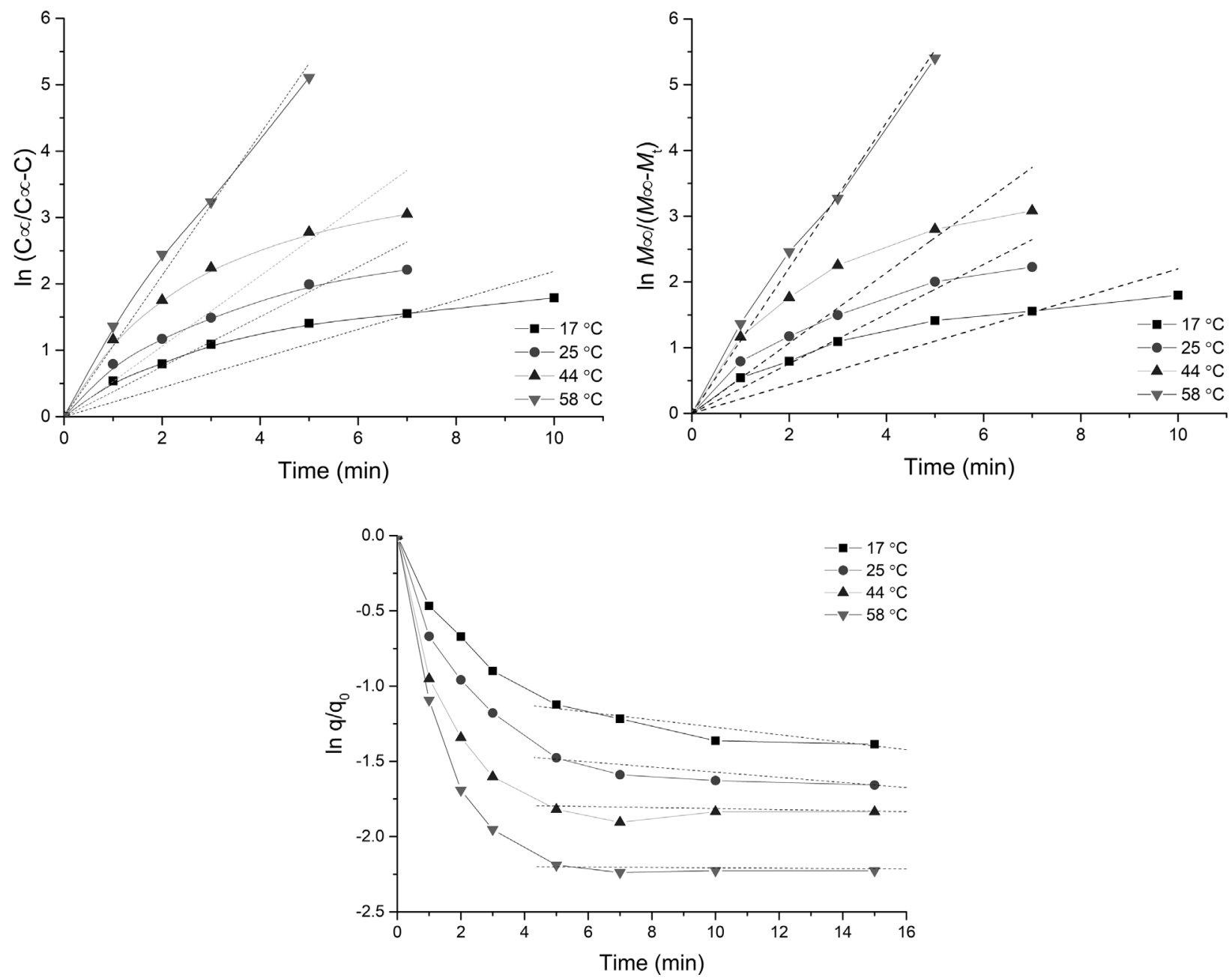

Figure 3: The dependence of (a) $\ln \left[C_{\infty} / C_{\infty}-C\right]$, (b) $\ln \left[M_{\infty} / M_{\infty}-M_{\mathrm{t}}\right]$, (c) $\ln q / q_{0}$ vs. time of caffeine extraction under the action of UESC (the dashed line shows a linear fit).

the solvent into the solid matrix, b) solvent penetration and diffusion inside the solid matrix, c) solubilization of the soluble compound, d) solute transport to the surface of the solid matrix by diffusion, e) migration of the extraction solute from external surface into the bulk solution.

The basic assumptions of the Jander 3D model [25], are:

1) The solid phase consisted of $N$ spherical shape particles, with the defined radius $\left(r_{o}\right)$;

2) The activity of the reactants does not change on either side of the reaction surface;

3) The product of the reaction does not affect the reactants;

4) The surface of the reactant is continually covered by the particles of the second reactant;

5) The volume diffusion of the reactant takes place in one direction;
6) The diffusion coefficient $(D)$ of the migrating reactant is not a function of time $(t)$;

7) The growth of the reactive surface layer takes place along the parabolic low:

$$
d_{t}^{2}=2 k D t
$$

where $d_{t}$ is thickness of the product layer, $k$ is rate constant of diffusion, $D$ is diffusion coefficient of migrating specie, and $t$ is time of reaction.

8) The chemical reaction at a phase boundary is faster than the rate of the transfer of reactant. In that case, volume of unreacted ratio of solid phase in time $(t)$ is given by equation:

$$
V_{t}=N \frac{4 \pi}{3}\left(r_{0}-d_{t}\right)^{3}
$$

Volume of unreacted ratio of solid phase can be calculated using following equation: 


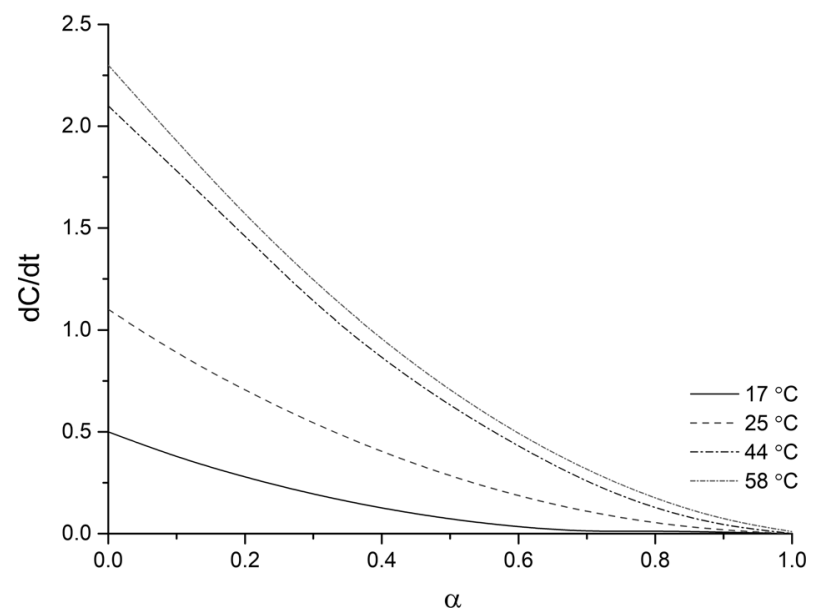

Figure 4: The changes of $\mathrm{dC} / \mathrm{dt}$ on degree of caffeine extraction.

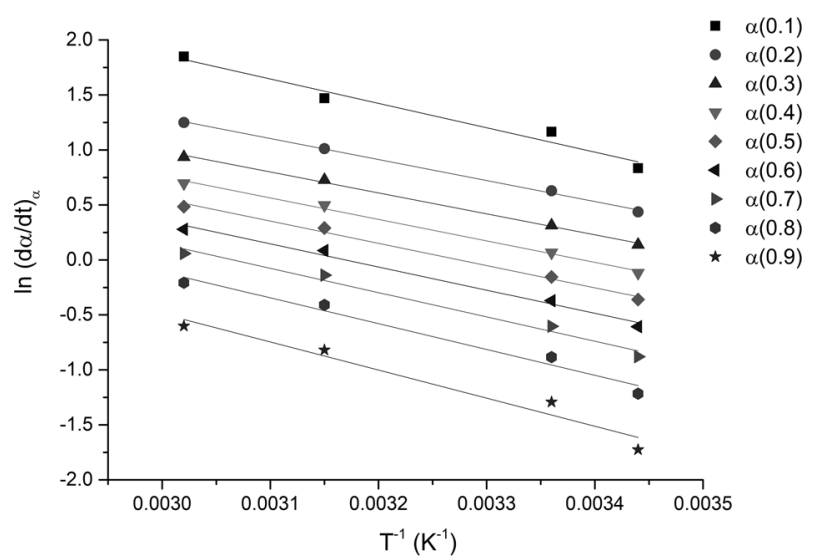

Figure 5: The dependence of $\ln (\mathrm{d} \alpha / \mathrm{d} t) \alpha$ on $T^{-1}\left(\mathrm{~K}^{-1}\right)$.

$$
V_{k}=N \frac{4 \pi}{3} r_{0}^{3}(1-\alpha)
$$

where $\alpha$ is conversion or extraction degree. By combining Eq. 10 and 11 and with rearranging, the thickness of the product layer can be expressed as follows:

$$
d_{t}=r_{0}\left[1-(1-\alpha)^{1 / 3}\right]
$$

By squaring both sides of Eq. 12 and by substituting Eq. 9 into the Eq. 12, following can be obtained:

$$
2 k D t=r_{0}^{2}\left[1-(1-\alpha)^{1 / 3}\right]^{2}
$$

If the: $\frac{2 k D}{r_{0}^{2}}=k_{M}$, we can obtain following:
\[ k_{M} \cdot t=\left[1-(1-\alpha)^{1 / 3}\right]^{2} \]

$$
k_{M} \cdot t=\left[1-(1-\alpha)^{1 / 3}\right]^{2}
$$

where $k_{\mathrm{M}}$ is a model rate constant.

Since the Jander theoretical 3D model can be used for a complete description of the kinetics of caffeine extraction from guarana seeds, with a high degree of certainty we claim that:

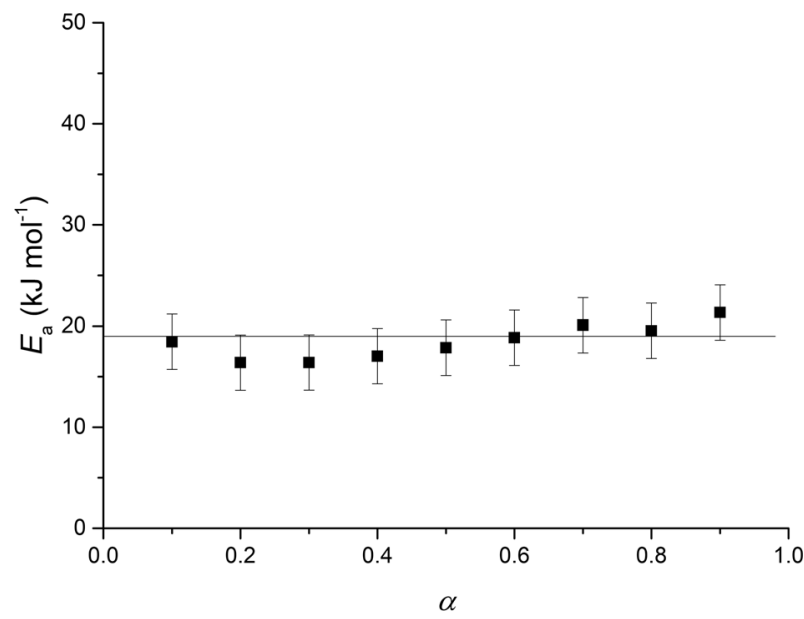

Figure 6: The dependence of $E_{\mathrm{a}}$ vs. the degree of caffeine extraction.

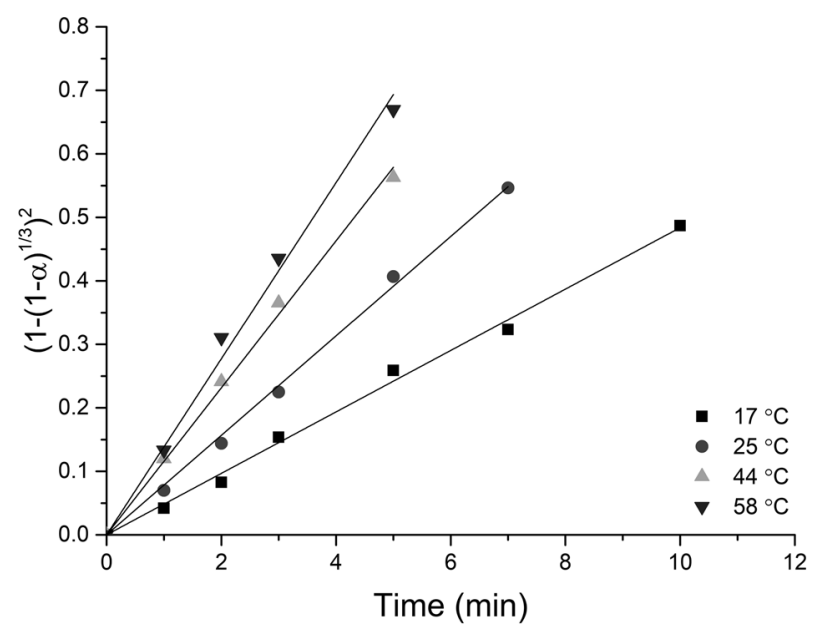

Figure 7: The dependence of $\left[1-(1-\alpha)^{1 / 3}\right]^{2}$ vs. time of caffeine extraction.

- the rate-limiting step of the investigated extraction is volume diffusion of water to the caffeine molecule;

- the volume diffusion of the reactant takes place in one direction;

- the diffusion coefficient $(D)$ of the migrating reactant is not a function of time $(t)$;

- the growth of the reactive surface layer takes place along the parabolic low.

In order to confirm the above statements and based on the knowledge of temperature dependence of the model rate constant $\left(k_{\mathrm{M}}^{\mathrm{UESC}}\right)$, by using the Arrhenius equation the values of kinetic parameters (activation energy $\left(E_{\mathrm{a}}{ }^{\mathrm{UESC}}\right)$ and pre-exponential factor $\left.\left(\ln A^{\mathrm{UESC}}\right)\right)$ for the investigated extraction process were determined. 
The values of the model rate constant $\left(k_{\mathrm{M}}{ }^{\mathrm{UESC}}\right)$ and kinetic parameters for the extraction of caffeine from guarana seed under the UESC is given in Table 1.

The value of activation energy of extraction of caffeine from guarana seed under the UESC calculated by using the differential isoconversional method was $E_{\mathrm{a}, \mathrm{\alpha}}=19.00 \pm$ $2.7 \mathrm{~kJ} \cdot \mathrm{mol}^{-1}$, which is in agreement with $E_{\mathrm{a}}$ obtained from the determined kinetic model which was found to be $E_{\mathrm{a}}=$ $19.4 \pm 3.5 \mathrm{~kJ} \cdot \mathrm{mol}^{-1}$. The $E_{\mathrm{a}}$ values obtained in the present study are in agreement also with those depicted in the literature for the kinetics of UAE of different bioactive compounds from the plant material. Jawade and Chavan reported $E_{\mathrm{a}}$ of $20.49 \mathrm{~kJ} \cdot \mathrm{mol}^{-1}$ for UAE of aloin from Aloe Vera gel within the temperature range from 30 to $50^{\circ} \mathrm{C}$ [26]. Tao et al. [18] noticed the values of $E_{\mathrm{a}}$ in the range from 16.5 to $19.9 \mathrm{~kJ} \cdot \mathrm{mol}^{-1}$ for UAE of phenols from grape marc at temperatures from 20 to $50^{\circ} \mathrm{C}$. Also, the value of $E_{\mathrm{a}}$ which is lower than $20 \mathrm{~kJ} \cdot \mathrm{mol}^{-1}$ was found to be distinctive for the extraction process which is managed by the diffusion [27].

By comparing the herein obtained kinetics results for caffeine extraction under the UESC with the isothermal caffeine extraction under conventional heating $(\mathrm{CH})$ and microwave heating $(\mathrm{MWH})$ published in our previous works [6,7], it can be concluded that the same kinetics model (Jander 3D model) can be used for describing the kinetics of caffeine extraction under the conditions of all these fields. The values of kinetic parameters $\left(E_{\mathrm{a}}\right.$ and $\ln A$ ) for process under the UESC was found to be lower than the values for the conventional heating conditions $\left(E_{\mathrm{a}}^{\mathrm{UESC}}=19.4 \mathrm{~kJ} \cdot \mathrm{mol}^{-1}, \ln A^{\mathrm{UESC}}=5.2 \mathrm{~min}^{-1} ; E_{\mathrm{a}}^{\mathrm{CH}}=\right.$ $21.8 \mathrm{~kJ} \cdot \mathrm{mol}^{-1}, \ln A^{\mathrm{CH}}=6.6 \mathrm{~min}^{-1}$ ) or higher than the values for the microwave heating conditions $\left(E_{\mathrm{a}}{ }^{\mathrm{MWH}}=17.1 \mathrm{~kJ} \cdot \mathrm{mol}^{-1}\right.$, $\ln A^{\mathrm{MWH}}=4.1 \mathrm{~min}^{-1}$ ).

Review of the literature $[28,29]$ suggests that combinations of various physical, mechanical, chemical and biochemical processes occur during application of ultrasound in extraction processes. The mechanism of UAE can be summarized as follows: a) enhanced mass transfer via turbulent mixing and acoustic streaming, b) surface damage at solvent-matrix interface by shock waves and microjets, c) high-velocity interparticle

Table 1: The model rate constant and kinetic parameters of caffeine extraction under the UESC.

\begin{tabular}{lclc}
\hline$T\left({ }^{\circ} \mathrm{C}\right)$ & $\boldsymbol{k}_{\mathrm{M}}^{\text {UESC }}\left(\mathrm{min}^{-1}\right)$ & \multicolumn{2}{c}{ Kinetic parameters } \\
\hline 17 & $0.0487 \pm 0.001$ & $E_{\mathrm{a}}^{\text {UESC }}\left(\mathrm{kJ} \cdot \mathrm{mol}^{-1}\right)$ & $\ln A^{\text {UESC }}\left(\mathrm{min}^{-1}\right)$ \\
25 & $0.0785 \pm 0.001$ & & \\
44 & $0.1158 \pm 0.002$ & $19.40 \pm 3.5$ & $5.2 \pm 1.4$ \\
58 & $0.1393 \pm 0.003$ & & \\
\hline
\end{tabular}

collisions, d) disintegration of matrix to increase surface area, e) occurrence of hot-points and overheating.

Because the overheating of the extraction system is ordinarily mentioned as a reason of acceleration of extraction rate, the influence of overheating on the kinetics of extraction is objectively determined. The knowledgeabout the calculated values of the rate constants for the caffeine extraction under the conventional heating conditions $\left(k_{\mathrm{M}}{ }^{\mathrm{CH}}\right)$ and UESC conditions $\left(k_{\mathrm{M}}{ }^{\mathrm{UESC}}\right)$ enable to impartially determine if overheating leads to the acceleration of the extraction of caffeine. If we hypothesize that ultrasonic field does not have an influence on the values of the kinetic parameters of the extraction but only leads to the increase in the temperature of the extraction mixture, the following should be valid: a) $E_{\mathrm{a}}^{\mathrm{UESC}}=E_{\mathrm{a}}^{\mathrm{CH}}$ and $A^{\mathrm{UESC}}=A^{\mathrm{CH}}$, and b) the dependences of $k_{\mathrm{M}}{ }^{\mathrm{UESC}}$ and $k_{\mathrm{M}}{ }^{\mathrm{CH}}$ vs. temperature obeys the Arrhenius equation, we can claim that:

$$
K^{\star}=\frac{k_{M}^{\mathrm{UESC}}}{k_{M}{ }^{C H}}=\frac{A^{\mathrm{UESC}} \exp \left(-E_{\mathrm{a}}^{\mathrm{UESC}} / R T^{\mathrm{UESC}}\right)}{A^{C H} \exp \left(-E_{\mathrm{a}}^{C H} / R T\right)}
$$

where $K^{\star}$ is the increment of the value of the constant rate of caffeine extraction in conditions of simultaneous cooling and ultrasound field, the $T^{\mathrm{UESC}}$ is a hypothetical temperature in the extraction mixture to which experimentally determined value of the $k_{\mathrm{M}}^{\mathrm{UESC}}$ corresponds, and $T$ is experimentally temperature measured in UESC system. Based on the knowledge of the values for the rate constants $\left(k_{\mathrm{M}}{ }^{\mathrm{CH}}\right.$ and $\left.k_{\mathrm{M}}{ }_{\mathrm{UESC}}\right)$ by using the expression (Eq. 15$)$, the $T^{\mathrm{UESC}}$ can be concluded (Eq. 16, Table 2):

$$
T^{U E S C}=\frac{E_{\mathrm{a}}^{C H} \cdot T}{E_{\mathrm{a}}^{C H}-R T \ln K^{\star}}
$$

Considering the fact that the calculated values of $T^{\mathrm{UESC}}$ are about $35^{\circ} \mathrm{C}$ higher compared to the actually measured values of the temperature in ultrasonic reactor, which significantly exceed the accuracy of the ultrasonic reactor temperature measurement system $\left( \pm 1^{\circ} \mathrm{C}\right)$, it can be stated that the increase in values of the rate of extraction and decrease in values of kinetic parameters under the UESC is not incurred as a consequence of hot spots and overheating of a extraction mixture.

Table 2: The values of hypothetical temperature in the reaction mixture.

\begin{tabular}{lcc}
\hline $\boldsymbol{T}\left({ }^{\circ} \mathrm{C}\right)$ & $\boldsymbol{T}^{\mathrm{UESC}}\left({ }^{\circ} \mathrm{C}\right)$ & $\Delta \boldsymbol{T}\left({ }^{\circ} \mathrm{C}\right)$ \\
\hline 44 & 79 & 35 \\
58 & 92 & 34 \\
\hline where $\Delta T=T^{\text {UESC }}-T$ & &
\end{tabular}


By comparing the determined values of kinetic parameters for the process of caffeine extraction under the influence of the investigated physical fields (thermal, microwave, or ultrasound), then, it can be concluded that there is a distinctly defined linear relationship (compensation effect) between $E_{\mathrm{a}}$ and $\ln A$ under the influence of the investigated physical fields that can be described by the expression:

$$
\ln A_{F}=-4.99+0.53 \cdot E_{\mathrm{a}, F}
$$

where $E_{\mathrm{a}, \mathrm{F}}$ and $\ln A_{\mathrm{F}}$ are the activation energy and preexponential factor in a defined physical field (thermal, microwave, or ultrasound). The values $E_{\mathrm{a}, \mathrm{F}}$ and $\ln A_{\mathrm{F}}$ in thermal and microwave field are previously determined in our work [6].

When the values of kinetic parameters of caffeine extraction in conditions of different physical fields is compered, the existence of compensation relationship indicates that the mechanism of activation of caffeine is independent on the presence of physical field and can be explained with SET model [6,30]. Following this model, the values of the wave number of resonant vibrations $(v)$, vibration quantum number $(n)$ and anharmonicity parameter $(x)$ for extraction in the ultrasonic field, and under conventional and microwave heating are obtained and given in Table 3.

Considering the results which are given for the process of caffeine extraction from guarana seed in ultrasonic field (i.e. UESC), under conventional heating (i.e. conventional extraction) and under microwave heating (i.e. microwaveassisted extraction) (Table 3), it is possible to conclude that ultrasonic field is not causing changes in the mechanism of the activation of the caffeine molecule for the extraction process. Thus, the mechanism of activation of caffeine molecule for the extraction process under ultrasonic field is identical as the process of extraction under $\mathrm{CH}$ and $\mathrm{MWH}$, and it is produced via selective transfer of required energy $\left(E_{\mathrm{a}}\right)$ from solvent (water) to the resonant vibration mode of the caffeine molecule. The calculated wave number of resonant vibrations $\left(v=317 \mathrm{~cm}^{-1}\right)$ which is the

Table 3: The values of $v, n$ and $x$ for caffeine extraction under influence of US, $\mathrm{CH}$, and $\mathrm{MWH}$.

\begin{tabular}{lccc}
\hline Variable & Ultrasonic field & $\begin{array}{c}\text { Conventional } \\
\text { heating* }\end{array}$ & $\begin{array}{c}\text { Microwave } \\
\text { heating* }\end{array}$ \\
\hline $\mathrm{v}\left(\mathrm{cm}^{-1}\right)$ & 317 & 317 & 317 \\
$n$ & 5 & 6 & 4 \\
$x$ & $-0,019$ & -0.028 & $-0,012$ \\
\hline
\end{tabular}

* Reference [6] same for the extraction process under the influence of all three physical fields (ultrasonic, thermal and microwave), correspond to the $\mathrm{N} 3-\mathrm{CH}_{3}$ (in-plane) bending vibration in caffeine molecule [31]. Moreover, the calculated wave number of vibrations is relatively close to libration motions of the water molecules which according to DominguezVidal et al. [32] occur above $300 \mathrm{~cm}^{-1}$ and with which the caffeine molecule is in resonance. Taking into account these results, the established decrease in values of $E_{\mathrm{a}}$ of the process of caffeine extraction under the influence of both, the ultrasonic and microwave field, could be explained with the fewer number of quanta required to activate the caffeine molecule for the extraction process in these fields relative to the thermal field. Reduced number of necessary quanta is most presumably caused by the increased energy of the ground resonant vibrational mode of the caffeine molecule which is a consequence of absorption of the energy from the ultrasonic and microwave fields. This absorption of energy leads to the increase in extraction rate and the decrease in kinetic parameters of the process of caffeine extraction from guarana seed under the influence of ultrasonic and microwave field, compared to the thermal field. Furthermore, the lower value of $\ln A$ for the process under the UESC and $\mathrm{MWH}$, compared to the thermal field is confirmed with the higher values of anharmonicity factor.

\section{Conclusions}

The shape of the established kinetic curves of caffeine extraction under the action of the ultrasonic field with simultaneous cooling does not change with the temperature. With increasing the temperature of a process in the ultrasonic field, the rate of extraction and maximal degree of extraction are increased. The kinetics of caffeine extraction under the UESC cannot be modelled by the most commonly employed kinetic models (Spiro's model; model based on Fick's second law of diffusion and model of non-steady state diffusion). The activation energy of the investigated process under the UESC is independent on the degree of caffeine extraction thus confirming the existence of one rate-limiting step of the investigated process. The Jander 3D model can describe the process of extraction of caffeine from guarana seed which is performed in conditions of the ultrasonic field. Energy consumption of UESC is found to be at least 4 times lower than for conventional conditions $\left(E_{\text {eff }}^{\text {UESC }}=2 \cdot 10^{6} \mathrm{~J} / \mathrm{g} ; E_{\text {eff }}^{\mathrm{CH}}=\right.$ $9 \cdot 10^{6} \mathrm{~J} / \mathrm{g}$ ). The calculated value of activation energy of the process of caffeine extraction under the action of ultrasonic field is lower than $E_{\mathrm{a}}$ of the same process under 
conventional heating, and higher when compared with the values of $E_{\mathrm{a}}$ of microwave-assisted extraction. The decrease in kinetic parameters $\left(E_{\mathrm{a}}, \ln A\right)$ of the process of caffeine extraction under the UESC and the potential explanation of the effects of the ultrasonic field on the kinetics of extraction of caffeine from guarana seed is provided by applying the SET model.

Acknowledgements: The investigation was supported by the Ministry of Education, Science and Technological Development of Republic of Serbia. Project No. OI 172015.

\section{References}

[1] Schimpl F.C., da Silva J.F., de Carvalho Gonçalves J.F., Mazzafera P., Guarana: Revisiting a highly caffeinated plant from the Amazon. J. Ethnopharmacol., 2013, 150, 14-31.

[2] Hamerski L, Somner G.V., Tamaio N., Paullinia cupana Kunth (Sapindaceae): A review of its ethnopharmacology, phytochemistry and pharmacology. J. Med. Plant. Res., 2013, 7(30), 2221-2229.

[3] Dalonso N., de Oliveira Petkowicz C.L., Guarana powder polysaccharides: Characterisation and evaluation of the antioxidant activity of a pectic fraction. Food Chem., 2012, 134(4), 1804-1812.

[4] Guglielmetti A., D’Ignoti V., Ghirardello D., Belviso S., Zeppa G., Optimisation of ultrasound and microwave-assisted extraction of caffeoylquinic acids and caffeine from coffee silverskin using response surface methodology. Ital. J. Food Sci., 2017, 29(3), 409-423.

[5] Jun X., Caffeine extraction from green tea leaves assisted by high pressure processing. J. Food Eng., 2009, 94(1), 105-109.

[6] Adnadjevic B., Koturevic B., Jovanovic J., Comparative kinetic analysis of isothermal extraction of caffeine from guarana seed under conventional and microwave heating. Chem. Eng. Res. Des., 2017, 118, 61-70.

[7] Koturevic B., Adnadjevic B., Jovanovic J., Isothermal green microwave-assisted extraction of caffeine from guarana: a kinetic study. Green Process. Synth., 2017, 6(6), 555-563.

[8] Preece K.E., Hooshyar N., Krijgsman A.J., Fryer P.J., Zuidam N.J., Pilot-scale ultrasound-assisted extraction of protein from soybean processing materials shows it is not recommended for industrial usage. J. Food Eng., 2017, 206, 1-12.

[9] Adewuyi Y.G., Sonochemistry: Environmental Science and Engineering Applications. Ind. Eng. Chem. Res., 2001, 40(22), 4681-4715.

[10] Boussetta N., Vorobiev E., Deloison V., Pochez F., FalcimaigneCordin A., Lanoisellé J.L., Valorisation of grape pomace by the extraction of phenolic antioxidants: application of high voltage electrical discharges. Food Chem., 2011, 128(2), 364-370.

[11] Veličković D.T., Milenović D.M., Ristić M.S., Veljković V.B., Kinetics of ultrasonic extraction of extractive substances from garden (Salvia officinalis L.) and glutinous (Salvia glutinosa L.) sage. Ultrason. Sonochem., 2006, 13(2), 150-156.

[12] Xi J., Yan L., He L., Pressure-dependent kinetic modeling of solid-liquid extraction of the major green tea constituents. Sep. Purif. Technol., 2014, 133, 155-159.

[13] Amarni F., Kadi H., Kinetics study of microwave-assisted solvent extraction of oil from olive cake using hexane: Comparison with the conventional extraction. Innovative Food Sci. Emerg. Technol., 2010, 11(2), 322-327.

[14] Pan Z., Qu W., Ma H., Atungulu G.G., McHugh T.H., Continuous and pulsed ultrasound-assisted extractions of antioxidants from pomegranate peel. Ultrason. Sonochem., 2012, 19(2), 365-372.

[15] Spiro M., Jaganyi D., Broom M.C., Kinetics and equilibria of tea infusion: Part 9. The rates and temperature coefficients of caffeine extraction from green Chun Mee and black Assam Bukial teas. Food Chem., 1992, 45(5), 333-335.

[16] Xiao X., Song W., Wang J., Li G., Microwave-assisted extraction performed in low temperature and in vacuo for the extraction of labile compounds in food samples. Anal. Chim. Acta, 2012, 712, 85-93.

[17] Bonfigli M., Godoy E., Reinheimer M.A., Scenna N.J., Comparison between conventional and ultrasound-assisted techniques for extraction of anthocyanins from grape pomace. Experimental results and mathematical modeling. J. Food Eng., 2017, 7, 56-72.

[18] Tao Y., Zhang Z., Sun D.W., Kinetic modeling of ultrasoundassisted extraction of phenolic compounds from grape marc: Influence of acoustic energy density and temperature. Ultrason. Sonochem., 2014, 21(4), 1461-1469.

[19] Stanisavljević, I.T., Lazić, M.L., Veljković, V.B., Ultrasonic extraction of oil from tobacco (Nicotiana tabacum L.) seeds. Ultrason. Sonochem., 2007, 14(5), 646-652.

[20] Yao L.H., Liu X., Jiang Y., Caffin N., D’Arcy B., Singanusong R., et al., Compositional analysis of teas from Australian supermarkets. Food Chem., 2006, 94(1), 115-122.

[21] Wanyika H.N., Gatebe E.G., Gitu L.M., Ngumba E.K., Maritim C.W., Determination of caffeine content of tea and instant coffee brands found in the Kenyan market. Afr. J. Food Sci., 2010, 4(6), 353-358.

[22] Simon P., The concept of single-step approximation and the non-Arrhenian kinetics in modelling the processes occurring in foods. J. Food Nutr. Res., 2011, 50(2), 133-138.

[23] Friedman H., Kinetics of thermal degradation of char-forming plastics from thermogravimetry. Applications to a phenol plastic. J. Polym. Sci. 6C, 1963, 6(1), 183-195. 
[24] Brown M.E., Dollimore D., Galway A.K., Reaction in the Solid State. In: Bamford C.H., Tipper C.F.H. (Eds.), Comprehensive Chemical Kinetics. Elsevier, Amsterdam, 1980.

[25] Jander W., Reaktionen im festen Zustande bei höheren Temperaturen. II. Mitteilung. Reaktionsgeschwindigkeiten exotherm verlaufender Umsetzungen. Zeitschrift für anorganische und allgemeine Chemie, 1927, 166, 31-52.

[26] Jawade N.R., Chavan A.R., Ultrasonic-Assisted Extraction of Aloin from Aloe Vera Gel. Procedia Eng., 2013, 51, 487-493.

[27] González-Centeno M.R., Comas-Serra F., Femenia A., Rosselló C., Simal S., Effect of power ultrasound application on aqueous extraction of phenolic compounds and antioxidant capacity from grape pomace (Vitis vinifera L.): Experimental kinetics and modeling. Ultrason. Sonochem., 2015, 22, 506-514.
[28] Dolatowski Z.J., Stadnik J., Stasiak D., Applications of ultrasound in food technology. Acta Sci. Pol. Technol. Aliment., 2007, 6(3), 88-99.

[29] Gigov M., Adnadjevic B., Jovanovic J., Effect of Ultrasonic Field on Isothermal Kinetics of Fullerene Polyhydroxylation. Sci. Sinter., 2016, 48(2), 259-272.

[30] Larsson R., A model of selective energy transfer at the active site of the catalyst. J. Mol. Catal., 1989, 55(1), 70-83.

[31] Srivastava S.K., Singh V.B., Ab initio and DFT studies of the structure and vibrational spectra of anhydrous caffeine. Spectrochim. Acta A, 2013, 115, 45-50.

[32] Dominguez-Vidal A., Kaun N., Ayora-Cañada M.J., Lendl B., Probing Intermolecular Interactions in Water/Ionic Liquid Mixtures by Far-infrared Spectroscopy. J. Phys. Chem. B, 2007, 111(17), 4446-4452. 